\title{
Numerical modelling of the thermospheric and ionospheric effects of magnetospheric processes in the cusp region
}

\author{
A. A. Namgaladze $^{1,2}$, A. N. Namgaladze $^{1}$, M. A. Volkov ${ }^{1}$ \\ ${ }^{1}$ Polar Geophysical Institute, 15 Halturina St., Murmansk, 183010, Russia \\ 2 Murmansk State Technical University, 2 Sportivnaya St., Murmansk, 183010, Russia
}

Received: 1 March 1996/Revised: 21 June 1996/Accepted: 25 June 1996

\begin{abstract}
The thermospheric and ionospheric effects of the precipitating electron flux and field-aligned-current variations in the cusp have been modelled by the use of a new version of the global numerical model of the Earth's upper atmosphere developed for studies of polar phenomena. The responses of the electron concentration, ion, electron and neutral temperature, thermospheric wind velocity and electric-field potential to the variations of the precipitating $0.23-\mathrm{keV}$ electron flux intensity and fieldaligned current density in the cusp have been calculated by solving the corresponding continuity, momentum and heat balance equations. Features of the atmospheric gravity wave generation and propagation from the cusp region after the electron precipitation and field-aligned currentdensity increases have been found for the cases of the motionless and moving cusp region. The magnitudes of the disturbances are noticeably larger in the case of the moving region of the precipitation. The thermospheric disturbances are generated mainly by the thermospheric heating due to the soft electron precipitation and propagate to lower latitudes as large-scale atmospheric gravity waves with the mean horizontal velocity of about $690 \mathrm{~m} \mathrm{~s}^{-1}$. They reveal appreciable magnitudes at significant distances from the cusp region. The meridional-windvelocity disturbance at $65^{\circ}$ geomagnetic latitude is of the same order $\left(100 \mathrm{~m} \mathrm{~s}^{-1}\right)$ as the background wind due to the solar heating, but is oppositely directed. The ionospheric disturbances have appreciable magnitudes at the geomagnetic latitudes $70^{\circ}-85^{\circ}$. The electron-concentration and -temperature disturbances are caused mainly by the ionization and heating processes due to the precipitation, whereas the ion-temperature disturbances are influence strongly by Joule heating of the ion gas due to the electricfield disturbances in the cusp. The latter strongly influence the zonal- and meridional-wind disturbances as well via the effects of ion drag in the cusp region. The results obtained are of interest because of the location of the
\end{abstract}

Correspondence to: A. A. Namgaladze
EISCAT Svalbard Radar in the cusp region and the associated observations at lower latitudes that will be possible using the existing EISCAT UHF and VHF radars. The paper makes predictions for both these regions, and these predictions will be tested by joint observations by ESR, EISCAT UHF/VHF and other ground-based ionosphere/thermosphere observations.

\section{Introduction}

The cusp is a region where magnetosheath solar-wind particles have direct access to the magnetosphere and some of them may precipitate into the ionosphere. The local ionospheric effects of the soft electron precipitation in the cusp, such as increases in the F2-region electron concentration and temperature, are well known (Shepherd, 1979). They have been modelled numerically, for example, by Roble and Rees (1977) by the use of the time-dependent, one-dimensional ionospheric model. The thermospheric effects of the soft electron precipitation are non-local, due to the internal atmospheric gravity waves propagating from the region of the abrupt electron precipitation. The same can be said of the ionospheric and thermospheric effects of the field-aligned current variations in the cusp because they influence the whole pattern of the polar ionosphere convection and related thermospheric disturbances. This means that these effects should be modelled by the use of the three-dimensional, time-dependent, self-consistent, ionospheric-thermospheric model including the electric-field calculations.

In recent years, the two- and three-dimensional thermospheric models have been used to study the response of the thermospheric to the model electric field and auroral-particle-precipitation variations (Richmond and Matsushita, 1975; Fuller-Rowell and Rees, 1981, 1984; Fuller-Rowell, 1984; Roble et al., 1987; Maeda et al., 1989; Burns et al., 1991; Fuller-Rowell et al., 1991). A modelling 
study of the effect of a short-lived, localized enhancement in the high-latitude dawnside convection electric field has been made using the coupled ionospheric/thermosphere model (Millward et al., 1993). However, the magnetospheric convection electric-field variations were not calculated but taken as inputs in all these model simulations, and the cusp region was not considered as a separate high-latitude source of the thermospheric and ionospheric disturbances. This source has some specific features in comparison with other auroral sources being more localized in longitude and having lower characteristic energies of the precipitating electrons.

The main goal of this paper is to investigate the thermospheric and ionospheric effects of the soft electron precipitation and field-aligned current variations in the cusp, of the order of an hour in duration, using a new version of the global numerical model of the Earth's upper atmosphere developed for studies of polar phenomena [Namgaladze et al., 1995 (1996a)]. This three-dimensional, time-dependent model describes the ionospheric, thermosphere and protonosphere of the Earth as a single system, and includes the calculations of the electric fields both of magnetospheric and thermospheric (dynamo) origin. The questions wanted to be answered in our investigation are the following: How far from the cusp can the thermospheric and ionospheric effects of the precipitation be seen? How does the spatial distribution of the electricfield potential react to the variations of the field-aligned currents in and near the cusp? How do these electric-field changes influence the disturbances of the thermospheric temperature and circulation and ionospheric parameters? What is the relative role of the electric-field penetration at remote distances from the cusp and atmospheric gravity wave propagation there?

The answers to these questions are of interest because of the location of the EISCAT Svalbard Radar in the cusp region and the associated observations at lower latitudes that will be possible using the existing EISCAT UHF and VHF radars. This paper makes predictions for both these regions and these predictions will be tested by joint observations by ESR, EISCAT UHF/VHF and other groundbased ionosphere/thermosphere observations.

\section{The model}

The global numerical model of the Earth's upper atmosphere (Namgaladze et al., 1988, 1990, 1991, 1994) has been constructed at the Kaliningrad Observatory of IZMIRAN and modified for the polar ionosphere studies at the Polar Geophysical Institute in Murmansk [Namgaladze et al., 1995 (1996a)]. The model describes the thermosphere, ionosphere and protonosphere of the Earth as a single system by means of numerical integration of the corresponding time-dependent, three-dimensional continuity, momentum and heat balance equations for neutral, ion and electron gases, as well as the equation for the electric-field potential. It is the main difference of this global model from many others (e.g. Fuller-Rowell and Rees, 1980, 1983; Dickinson et al., 1981, 1984; FullerRowell et al., 1984, 1987, 1988; Roble et al., 1988; Schunk, 1988; Sojka, 1989; Sojka and Schunk, 1988, 1989; Richmond et al., 1992; Roble and Ridley, 1994) that not only winds, gas densities and temperatures of the thermosphere and ionosphere, but electric fields both of thermospheric dynamo and magnetospheric origin and protonospheric parameters are calculated in this model as well.

The model covers the height range from $80 \mathrm{~km}$ up to a geocentric distance of 15 Earth radii, and takes into account the offset between the geomagnetic and geographic axes of the Earth. It consists of three main blocks: thermospheric, ionospheric-protonospheric and

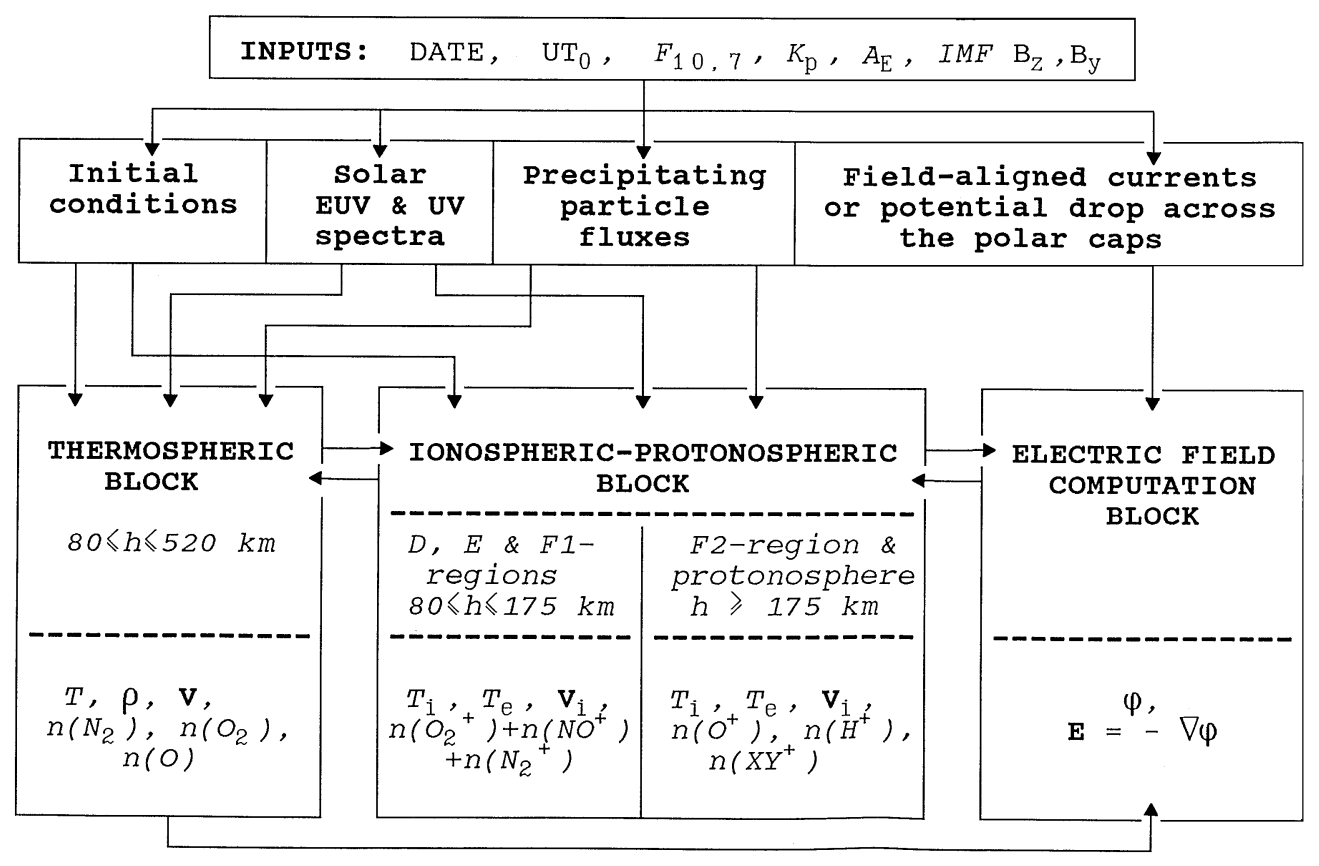

Fig. 1. Inputs, main computation blocks and outputs of the model 
electric-field computation blocks (see Fig. 1) using different coordinate systems and different spatial grids of numerical integration. The exchange of information between these blocks is carried out at every time step of the numerical integration of the modelling equations.

In these blocks the corresponding well-known hydrodynamical continuity, momentum and heat balance equations for the neutral, electron and ion gases as well as the equation for the electric-field potential are all solved numerically by the use of the finite difference methods to obtain the time and spatial variations of the following parameters: the total mass density $\rho$, concentrations of the main thermospheric gas constituents $n(\mathrm{O}), n\left(\mathrm{O}_{2}\right), n\left(\mathrm{~N}_{2}\right)$, the total concentration of the molecular ions $n\left(\mathrm{XY}^{+}\right)=$ $n\left(\mathrm{O}_{2}^{+}\right)+n\left(\mathrm{NO}^{+}\right)+n\left(\mathrm{~N}_{2}^{+}\right)$, concentrations of the atomic ions $n\left(\mathrm{O}^{+}\right)$and $n\left(\mathrm{H}^{+}\right)$, temperatures of the neutral, ion and electron gases $T_{n}, T_{i}$ and $T_{e}$, thermospheric wind and ion velocity vectors $\boldsymbol{V}_{n}$ and $\boldsymbol{V}_{i}$, the electric-field potential $\varphi$ and the electric-field intensity vector $\boldsymbol{E}$. The detailed description of the model equations, initial and boundary conditions can be found in Namgaladze et al. (1988).

In the thermospheric block the modelling equations are solved in a spherical geomagnetic coordinate system. The same coordinate system is used to calculate the concentration, velocity and temperature of the molecular ions as well as the electron temperature at heights $80-175 \mathrm{~km}$. The neutral-atmosphere parameters calculated in the spherical geomagnetic coordinate system are interpolated to the nodes of the finite difference magnetic dipole coordinate grid to calculate the parameters of the ionospheric F2 region and the protonosphere. In turn, the necessary parameters of the ion and electron gases are put into the thermospheric block from the ionospheric-protonospheric block which uses the electric field from the electric-field computation block. This latter block uses all necessary ionospheric and thermospheric parameters from the thermospheric and ionospheric-protonospheric blocks.

In our new version of this model [Namgaladze et al., 1995 (1996a)] we use the variable latitudinal steps of numerical integration. For the thermospheric and molecular ion parameters the latitudinal integration steps vary from $10^{\circ}$ at the geomagnetic equator to $2^{\circ}$ at the auroral zones; for the electric-field, ionospheric $\mathrm{F} 2$ region and protonospheric parameters they vary from $5^{\circ}$ at the geomagnetic equator to $2^{\circ}$ at the auroral zones. We have used this grid in the calculations presented below. Namgaladze et al. [1995 (1996a)] have shown that such a grid gives the results which do not differ significantly from those obtained with a regular grid using the constant $2^{\circ}$ step in geomagnetic latitude. The time step of integration is $2 \mathrm{~min}$. Other steps of the numerical integration are $15^{\circ}$ in geomagnetic longitude and variable in altitude: $3 \mathrm{~km}$ near the lower boundary $(h=80 \mathrm{~km}), 5 \mathrm{~km}$ near $h=115 \mathrm{~km}, \quad 15 \mathrm{~km}$ near $h=220 \mathrm{~km}, 25 \mathrm{~km}$ near $h=330 \mathrm{~km}$ and $40 \mathrm{~km}$ near $h=500 \mathrm{~km}$, giving 30 levels in the altitude range from 80 to $520 \mathrm{~km}$ for the thermospheric parameters. The number of the nodes of the grid along $\boldsymbol{B}$ for $\mathrm{F} 2$ region and protonospheric parameters varies from 9 on the lowest equatorial field line to maximum value 140 on the field line with $L=15$.

\section{The precipitating electron flux and field-aligned current variations}

The input parameters of the model are 1) solar UV and EUV spectra; 2) precipitating particle fluxes; 3) fieldaligned currents connecting the ionosphere with the magnetosphere. For the solar UV and EUV fluxes and their dependencies on solar activity we use the data from Ivanov-Kholodny and Nusinov (1987) for the low solar activity $\left(F_{10,7}=70\right)$. Intensities of night-sky scattered radiation are put equal to $5 \mathrm{kR}$ for $\lambda=121.6 \mathrm{~nm}$ and $5 \mathrm{R}$ for each of other emission lines $(\lambda \lambda=102.6,58.4$ and $30.4 \mathrm{~nm}$ ). Spatial distribution of the precipitating electron fluxes is taken at the upper boundary of the thermosphere $(h=520 \mathrm{~km})$ in a simple form:

$$
I(\Phi, \Lambda)=I_{m} \exp \left[-\left(\Phi-\Phi_{m}\right)^{2} /(\Delta \Phi)^{2}-\left(\Lambda-\Lambda_{m}\right)^{2} /(\Delta \Lambda)^{2}\right],
$$

where $\Phi$ and $\Lambda$ are geomagnetic latitude and longitude; $\Lambda=0$ corresponds to the midday geomagnetic meridian; $I_{m}$ is the maximum intensity of the precipitating electron flux; $\Phi_{m}, \Lambda_{m}$ are the geomagnetic latitude and longitude of the precipitation maximum; $\Delta \Phi, \Delta \Lambda$ charcterize latitudinal and longitudinal dimensions of the precipitation area, respectively. All these parameters can vary depending on geophysical conditions.

We modelled the effects of the soft electron precipitation in the cusp by the following means. The precipitating 0.23-keV electron flux (a Maxwellian with characteristic energy of $0.23 \mathrm{keV}$ ) intensity in the cusp region $I_{m}$ and the geomagnetic latitude of the precipitation maximum $\Phi_{m}$ have been used as the variable inputs of the model; $\Phi_{m}$ varies between $78^{\circ}$ and $73^{\circ}$ geomagnetic latitude; $\Delta \Phi=$ $3.5^{\circ} ; \Lambda_{m}$ corresponds to the local midday; $\Delta \Lambda=45^{\circ}$, i.e. the cusp region extends approximately from 9 to 15 MLT. The undisturbed value of $I_{m}$ has been chosen equal to $1.9 \times 10^{9} \mathrm{~cm}^{-2} \mathrm{~s}^{-1}$.

In the first variant of the calculations this flux was increased suddenly by a factor of 10 at 0000 UT and

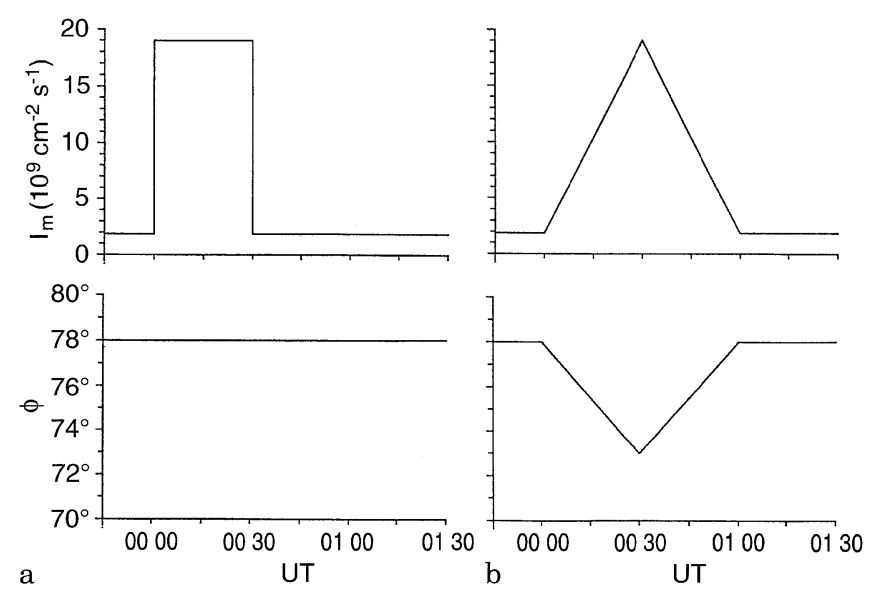

Fig. 2a, b. Time variations of the precipitating $0.23-\mathrm{keV}$ electron flux intensity (top) and geomagnetic latitude of the precipitation maximum (bottom) in a the fixed cusp position (left-hand plots) and b the moving (rigt-hand plots) 
Electron flux (0.23 keV), $\mathrm{cm}^{-2} \mathrm{~s}^{-1}$

\section{$030 \mathrm{UT}$}

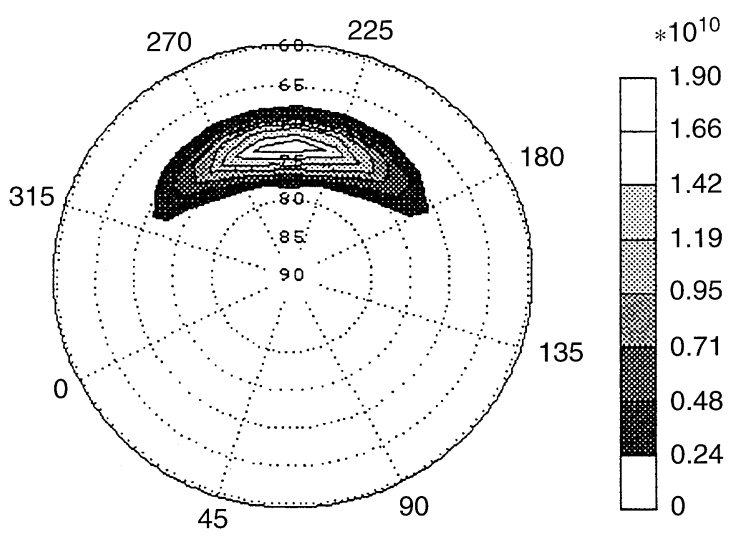

Fig. 3. Northern-hemisphere geomagnetic polar plot $\left(60^{\circ}-90^{\circ}\right)$ of the input precipitation flux of $0.23-\mathrm{keV}$ electrons in case of the moving cusp at $0030 \mathrm{UT}$ maintained at such a level for $30 \mathrm{~min}$ and then returned suddenly to the initial level. In the second variant of the calculations the precipitating electron flux intensity was increased linearly with time over $30 \mathrm{~min}$ from 0000 to 0030 UT. Simultaneously, the position of the intensity maximum moved from $78^{\circ}$ to $73^{\circ}$ geomagnetic latitude. During the next 30 min both maximum intensity and its position returned linearly to their initial levels. Such movements of the cusp have been observed, for example by Sandholt et al. (1994). The time-integrated peak flux of the precipitating electrons was the same in both variants of the calculations. The time variations of the precipitating electron flux intensity and cusp position for both variants of the calculations are shown in Fig. 2. In Fig. 3, the geomagnetic polar plot $\left(60^{\circ}-90^{\circ}\right)$ shows the precipitating $0.23-\mathrm{keV}$ electron flux intensity in case of the moving cusp at $0030 \mathrm{UT}$, which is the time of the maximum of the disturbance. The background quiet precipitations outside the cusp region were the same as in our previous papers for the quiet equinoctial conditions under low
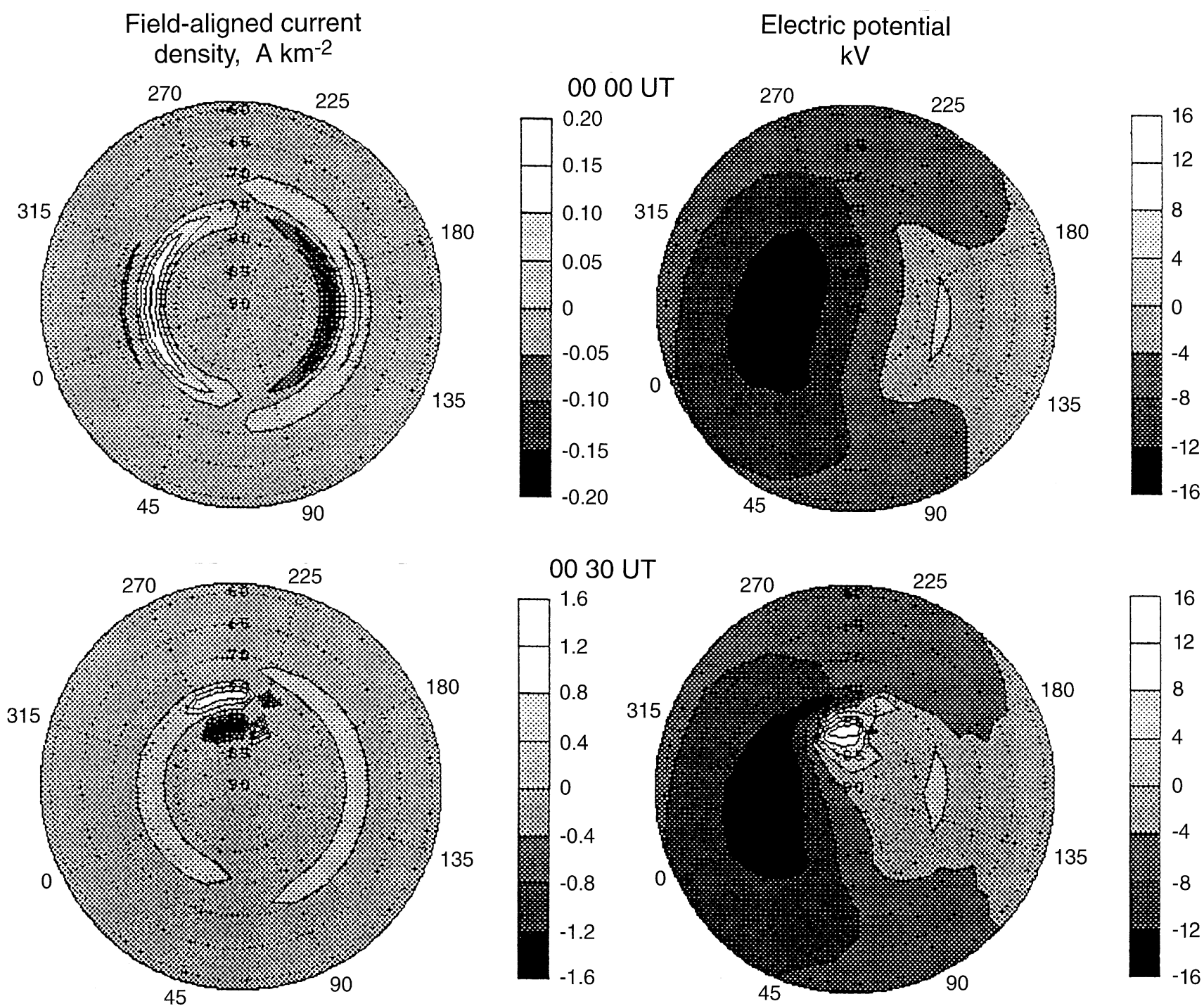

Fig. 4. Northern hemisphere geomagnetic polar plots $\left(60^{\circ}-90^{\circ}\right)$ of the input field-aligned current density (left-hand plots) and calculated

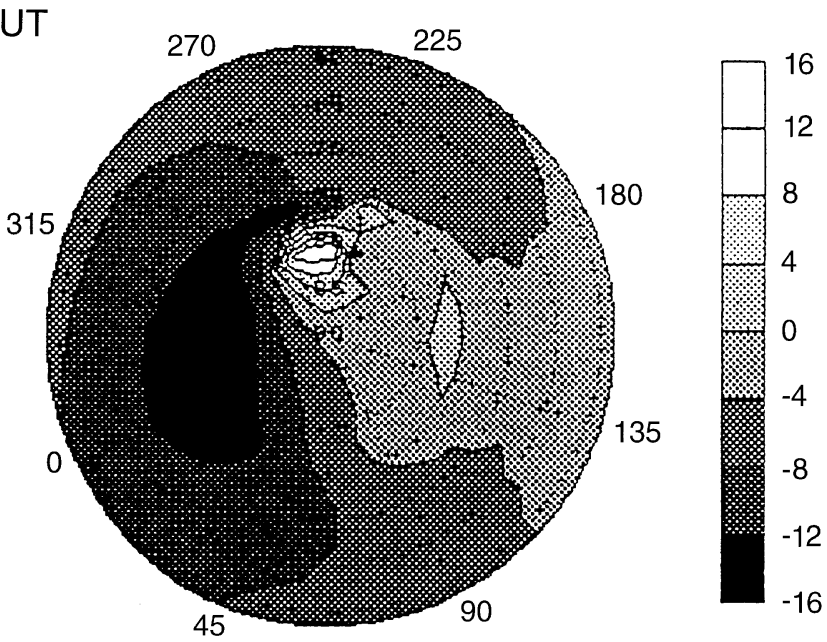

electric-field potential (right-hand plots) at $0000 \mathrm{UT}$ (top) and 0030 UT (bottom) 
solar activity (for example, Namgaladze et al., 1996b) being close to those given by Hardy et al. (1985). They were not varied in these calculations.

The magnetospheric sources of the electric field for the undisturbed conditions are field-aligned currents in zones 1 and 2 (Iijima and Potemra, 1976). The first zone of field-aligned currents, flowing into the ionosphere on the dawn and out on the duskside, is at the polar-cap boundary $\left( \pm 76^{\circ}\right.$ magnetic latitude). The second zone of the field-aligned currents flowing opposite to the zone-1 currents is located $4^{\circ}$ equatorward from zone 1 . The quiet field-aligned current density distribution in the north polar ionosphere at 0000 UT is shown here in Fig. 4 (lefthand, top panel).

To investigate the effects of the disturbed field-aligned current variations in the cusp for IMF $B_{y}<0$, we have used the following model input variations of the fieldaligned currents based on the data by Taguchi et al.
(1993), Yamauchi et al. (1993) and Ohtani et al. (1995). We have added the field-aligned current flowing into (resp. out of) the ionosphere at the northern (resp. southern) hemisphere along the $80^{\circ}$ geomagnetic latitude at the 1130-1400-MTL sector and flowing out at the 1000-1130MLT sector (left-hand, bottom panel in Fig. 4). These currents are closed by the additional zone-1 currents. All disturbed field-aligned currents are added to the quite field-aligned currents shown in the top left-hand panel in Fig. 4. The time variation of all these additional fieldaligned currents has the following form. Their density increases linearly from 0 to the maximum value during the first $30 \mathrm{~min}(0000-0030 \mathrm{UT})$ and then recovers to 0 during the next $30 \mathrm{~min}(0030-0100 \mathrm{UT})$. The maximum density of the field-aligned current flowing into the ionosphere at $80^{\circ}$ geomagnetic latitude is $1.6 \mathrm{~A} \mathrm{~km}^{-2}$, which is ten times larger than the quiet zone-1 field-aligned current density. The corresponding magnetic disturbance in the
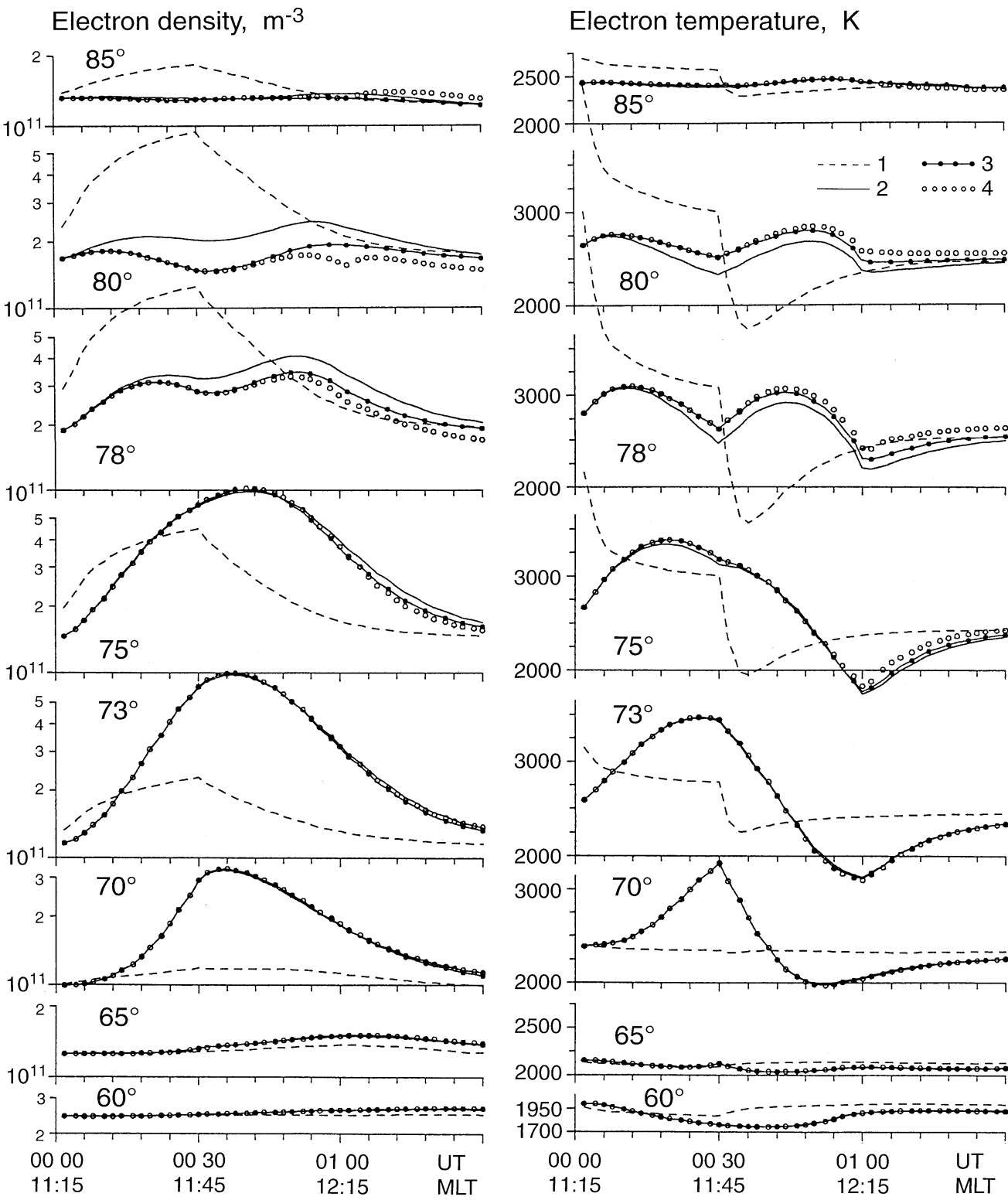

Fig. 5. Time variations of the calculated electron concentration (left-hand plots) and electron temperature (right-hand plots) at $h=300 \mathrm{~km}$, $\Lambda=240^{\circ}$, at various geomagnetic latitudes for variants 1 (dashed curves), 2 (solid curves), 3 (black-circle curves) and 4 (open circles) of the calculations (see text for explanation) 
cusp region is estimated approximately at $600 \mathrm{nT}$. Such a disturbance was observed in the cusp region when the $B_{y}$ component of IMF was equal $-9 \mathrm{nT}$ (Taguchi et al., 1993). It means that the modelled situation corresponds to the case when $B_{y}$ changes from 0 to $-9 \mathrm{nT}$ and back to 0 over a 1 -h period.

\section{The results of calculations and discussion}

Four variants of the calculations have been performed: (1) the cusp position is fixed and only the sudden precipitation of $0.23-\mathrm{keV}$ electrons takes place over $30 \mathrm{~min}$ (from 0000 to 0030 UT, see left-hand plots in Fig. 2); (2) the cusp is moving and the precipitation is linearly increased and then decreased over $1 \mathrm{~h}$ (see right-hand plots in Fig. 2); (3) the same as in variant 2 but the additional field-aligned currents are included being linearly increased and then decreased over $1 \mathrm{~h}$; (4) the same as in variant 3 but the additional field-aligned currents maintain their maximum values after $0030 \mathrm{UT}$.

The magnetosphere may generate these four cases by the following means. Variant 1 employs a square wave pulse of enhanced electron precipitation flux in the cusp region, which maintains a fixed position in the ionosphere. This could well be the result of a corresponding pulse in the density of the solar wind impinging on the magnetosphere. Such a pulse would compress the dayside magnetosphere but would not move the latitude of the dayside cusp in the ionosphere (because the ionosphere is largely incompressible, in the sense that the magnetic field there is almost constant).

Variant 2 has a triangular pulse in cusp electron flux, which again could be caused by a similar variation in the
Neutral temperature, $\mathrm{K}$

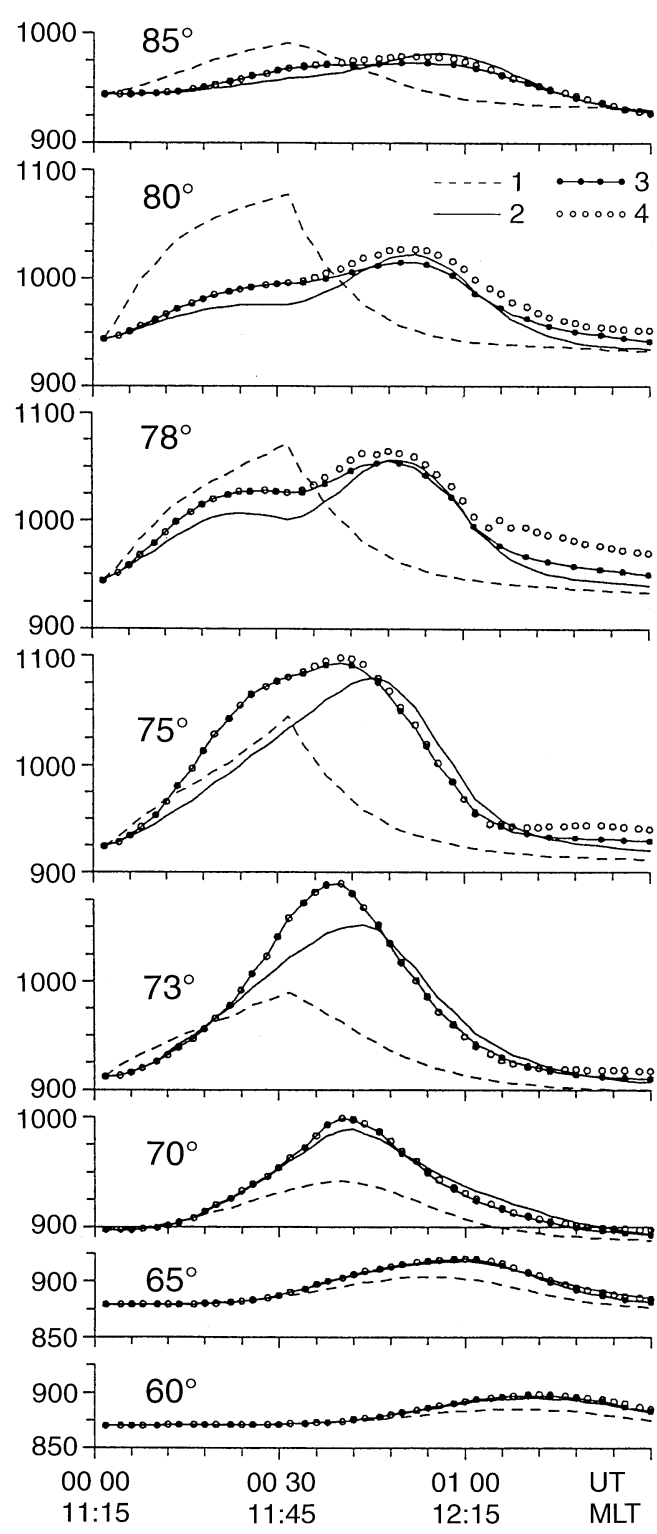

Ion Temperature, $\mathrm{K}$

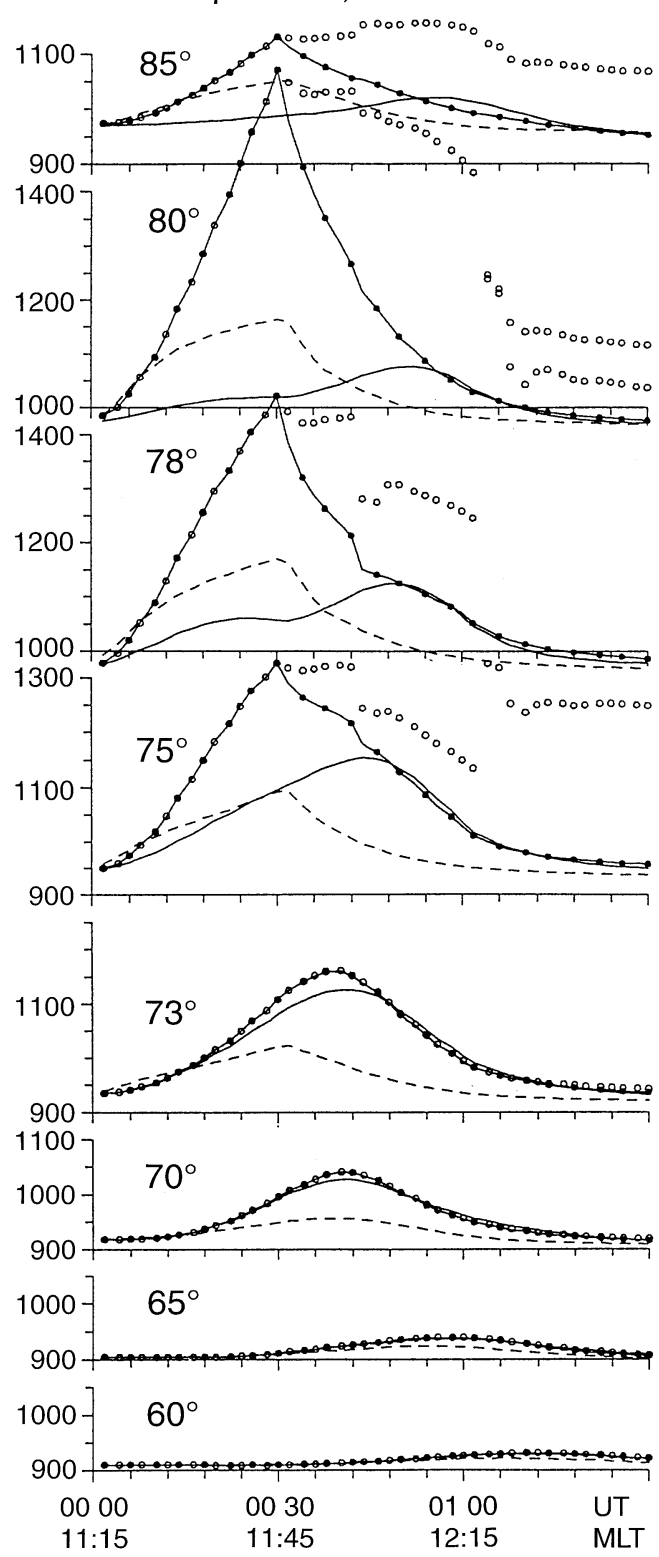

Fig. 6. The same as in Fig. 5 but for the neutral (left-hand plots) and ion (right-hand plots) temperature 
solar-wind density. The cusp migrates equatorwards, as is often seen in observations. This would be expected if the magnetopause compression were to be accompanied by a proportionally enhanced rate of magnetopause reconnection, eroding the dayside magnetopause and bringing the cusp to lower latitudes. However, we would also expect (after about a 10-15-min delay) this to cause a rise in the field-aligned currents and associated ionospheric convection (see for example Cowley and Lockwood, 1992). Thus variant 2 is unlikely to be observed. Nevertheless, it is useful to model variant 2 , as it helps distinguish the effects of the precipitation from those of the electrodynamics. We consider variant 3 , in which the erosion is accompanied by field-aligned currents in synchronization with erosion, to be more realistic than variant 2 .

Lastly, variant 4 does not ramp down the field-aligned currents after the rise; this means that the cusp-region currents and associated flows persist after the enhanced cusp precipitation decays. This would happen if the dayside reconnection persists after the decay of the solar-wind pressure pulse. This situation would thus apply to a southward turning of the IMF, occuring at the time of the solar-wind pressure pulse.

Figures 5-7 show the calculated time variations of the ionospheric and thermospheric parameters at various north geomagnetic latitudes in the range $60^{\circ}-85^{\circ}$ for the daytime $240^{\circ}$ geomagnetic meridian at the height $300 \mathrm{~km}$. Variants 1, 2, 3 and 4 of the calculations are presented in these figures by the dashed, solid, black-circle and opencircle curves, respectively.

Let us consider firstly the results of variants 1 and 2 of the calculations when only precipitation acts as a source of disturbance. As we can see in Figs. 5 and 6, at the geomagnetic latitudes equatorwards from about $75^{\circ}$, the disturbances of the electron concentration and temperature, as well as of the ion and neutral temperature, are
Northward wind, $\mathrm{m} \mathrm{s}^{-1}$
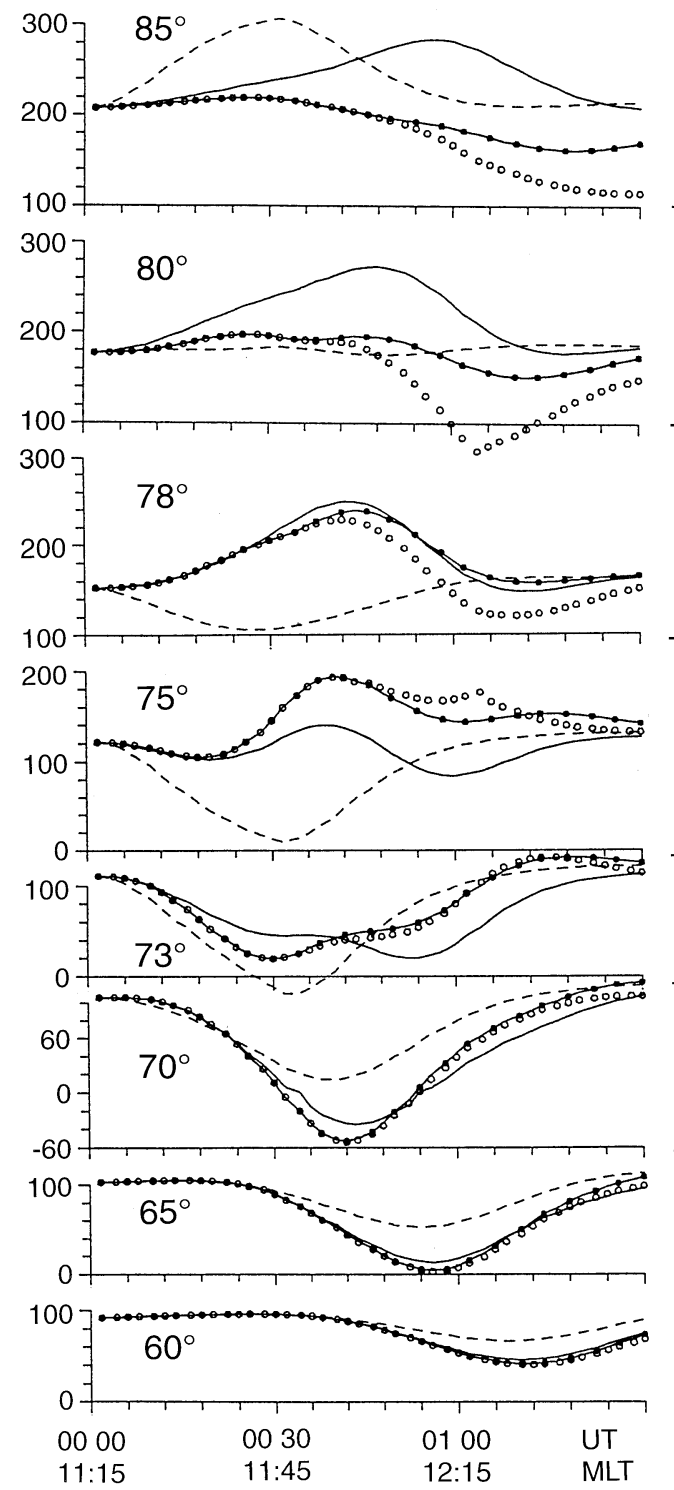

Eastward wind, $\mathrm{m} \mathrm{s}^{-1}$
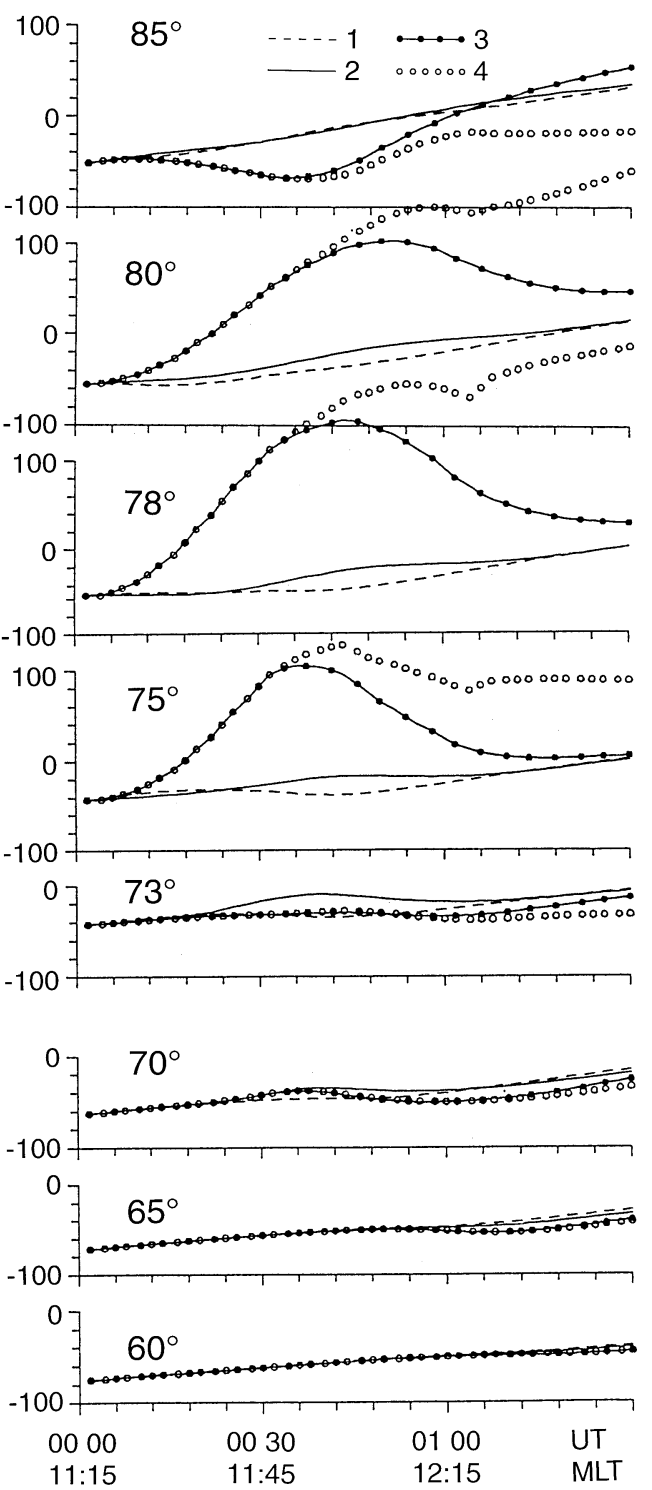

Fig. 7. The same as in Fig. 5 but for the meridional, positive northward (left-hand plots) and zonal, positive eastward (righthand plots) thermospheric wind velocity 
minimal in case of the fixed cusp position (variant 1 of the calculations). The exception for this is the initial electron temperature burst near the cusp region in the beginning of the abrupt precipitation. This burst takes place when the ion concentration is not yet high enough to cool the electron gas effectively.

At the end of the precipitation burst (0030 UT) in variant 1 , electron concentration $N_{e}$ at $h=300 \mathrm{~km}$ (lefthand plots in Fig. 5) reaches its maximum value of about $8.4 \times 10^{11} \mathrm{~m}^{-3}$ at $78^{\circ}$ geomagnetic latitude, in comparison with the initial value of about $2.9 \times 10^{11} \mathrm{~m}^{-3}$ at $0000 \mathrm{UT}$. This then decreases to the quiet level during the next $30 \mathrm{~min}$. In the case of the moving cusp (variant 2 of the calculations) $N_{e}(300 \mathrm{~km})$ reaches the maximum value of $6.7 \times 10^{11} \mathrm{~m}^{-3}$ at $0030 \mathrm{UT}$ at $73^{\circ}$ geomagnetic latitude, in comparison with the initial value of about $1.2 \times 10^{11} \mathrm{~m}^{-3}$, and recovers to the quite level at about 0130 UT. These $N_{e}$ enhancements are caused by the precipitating electron impact ionization, although there is also an increase of the ion $\mathrm{O}^{+}$loss rate due to the neutral-composition and

\section{Neutral temperature disturbance, $\mathrm{K}$}
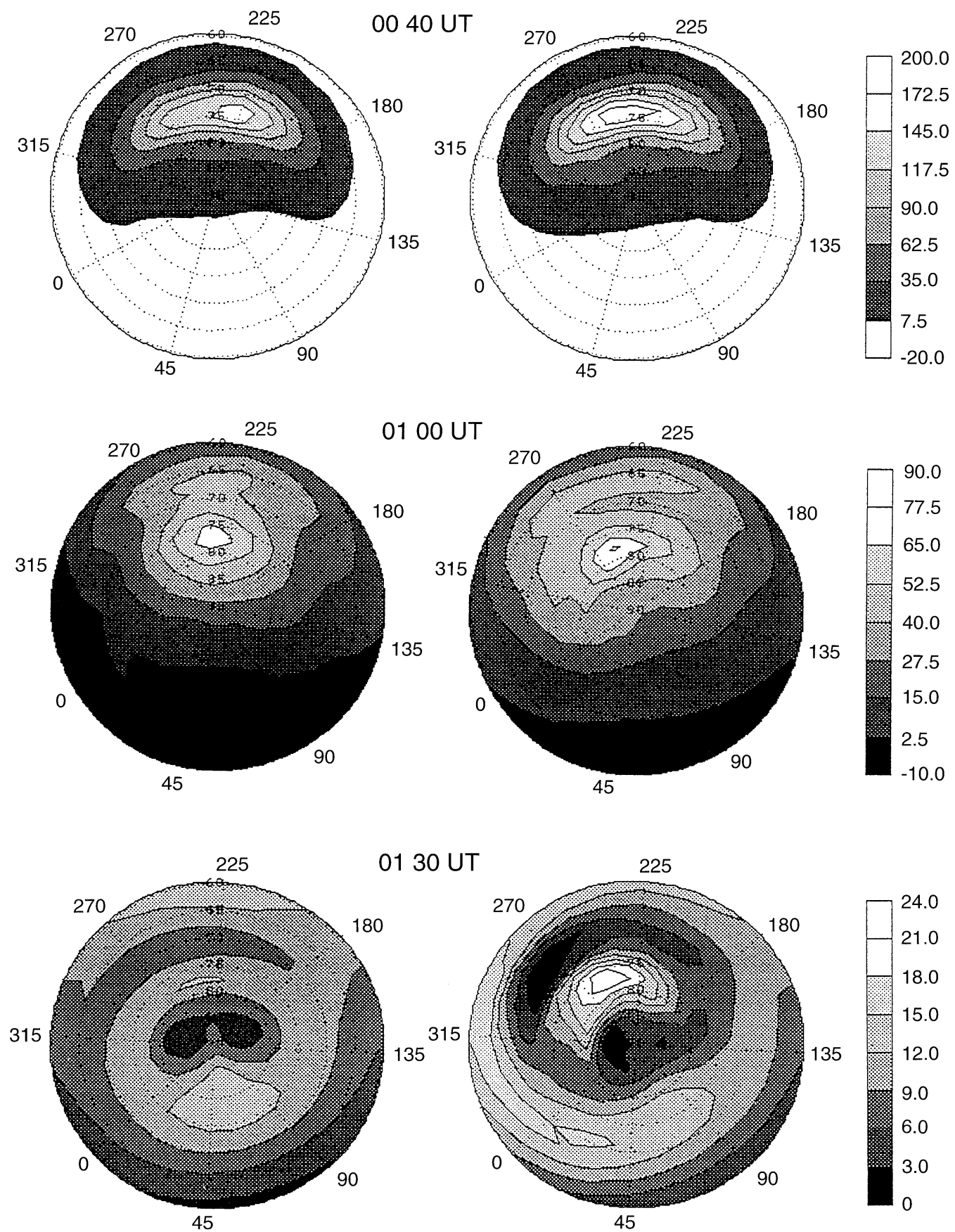

Fig. 8. North geomagnetic polar plots $\left(60^{\circ}-90^{\circ}\right)$ of the calculated neutral-temperature disturbance at $h=300 \mathrm{~km}$ in variants 2 (left-hand plots) and 3 (right-hand plots) of the calculations at 0040, 0100 and $0130 \mathrm{UT}$ 
ion-temperature disturbances. At $70^{\circ}$ geomagnetic latitude, the $N_{e}$ enhancement is still rather high in variant 2 of the calculations, whereas in variant 1 the disturbance magnitude drops very significantly. At lower latitudes, only weak positive disturbances of $N_{e}$ caused by the disturbed-thermospheric-wind action propagate equatorwards with average speed of about $540 \mathrm{~m} \mathrm{~s}^{-1}$ in both variants of the calculations as estimated for the $65^{\circ}-60^{\circ}$ latitude range.

The electron-temperature disturbances are shown in Fig. 5 (right-hand plots). They are positive in the cusp region for most of the time when the heating of the electron gas by the precipitating electrons is active, but become negative after the ending of the precipitation. This is because the remaining increased ion concentration acts to cool the electron gas.

The ion-temperature variations shown in Fig. 6 (righthand plots) are very similar to those of the neutral temperature (left-hand plots in Fig. 6), being more intensive in the case of the moving cusp (variant 2) at the geomagnetic latitudes lower than about $78^{\circ}$. Both ion- and neutraltemperature disturbances are positive due to the heating of the ion and neutral gases by electrons. They propagate away from the cusp region as large-scale gravity waves with the average speed of about $690 \mathrm{~m} \mathrm{~s}^{-1}$, estimated for the $70^{\circ}-60^{\circ}$ latitude range.
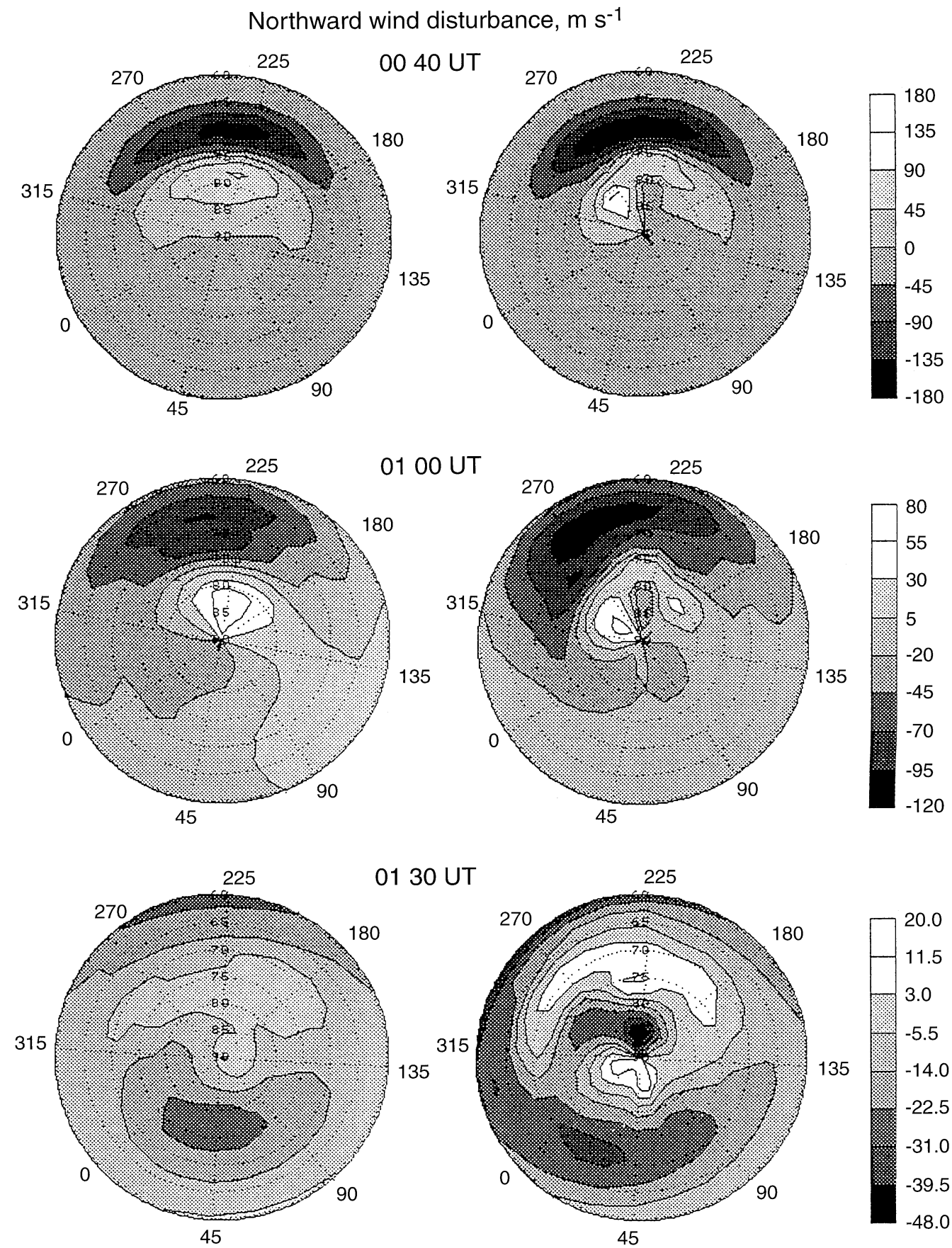

Fig. 9. The same as in Fig. 8 but for the meridional (positive northward) thermosphericwind-velocity disturbance at $48.0 \quad h=300 \mathrm{~km}$ 
The meridional thermospheric wind disturbances (lefthand plots in Fig. 7), driven by the pressure gradient forcing from the heated cusp region, reveal an analogous character of the propagation being of about 140,90 and $46 \mathrm{~m} \mathrm{~s}^{-1}$ in magnitude at the geomagnetic latitudes $70^{\circ}$, $65^{\circ}$ and $60^{\circ}$, respectively, in case of the moving cusp. The corresponding values are about 90,50 and $26 \mathrm{~m} \mathrm{~s}^{-1}$ at the same latitudes in case of the fixed cusp position. The zonal-wind disturbances (right-hand plots in Fig. 7) are insignificant in the midday sector for cases when only enhanced precipitation takes place. The neutral-composition disturbances (not shown) are virtually confined to the cusp region where the concentration $\mathrm{O} / \mathrm{N}_{2}$ ratio diminishes by about $25 \%$ at $75^{\circ}$ geomagnetic latitude in case of the moving cusp, and $24 \%$ at $80^{\circ}$ in case of the fixed cusp position.

Now let us consider the results of the calculations in variants 3 and 4 where the additional field-aligned currents in the cusp region are included as shown in Fig. 4. These have largest current densities at 0030 UT and subsequently either return to the quiet at 0100 UT (variant 3) or remain fixed at their maximum values (variant 4).

The calculated electric-field-potential patterns in the north polar ionosphere are shown in Fig. 4 (right-hand plots). The undisturbed potential pattern (top panel) consists of two well-known convection cells with positive potential values in the morning sector and with the negative potential values in the evening sector corresponding
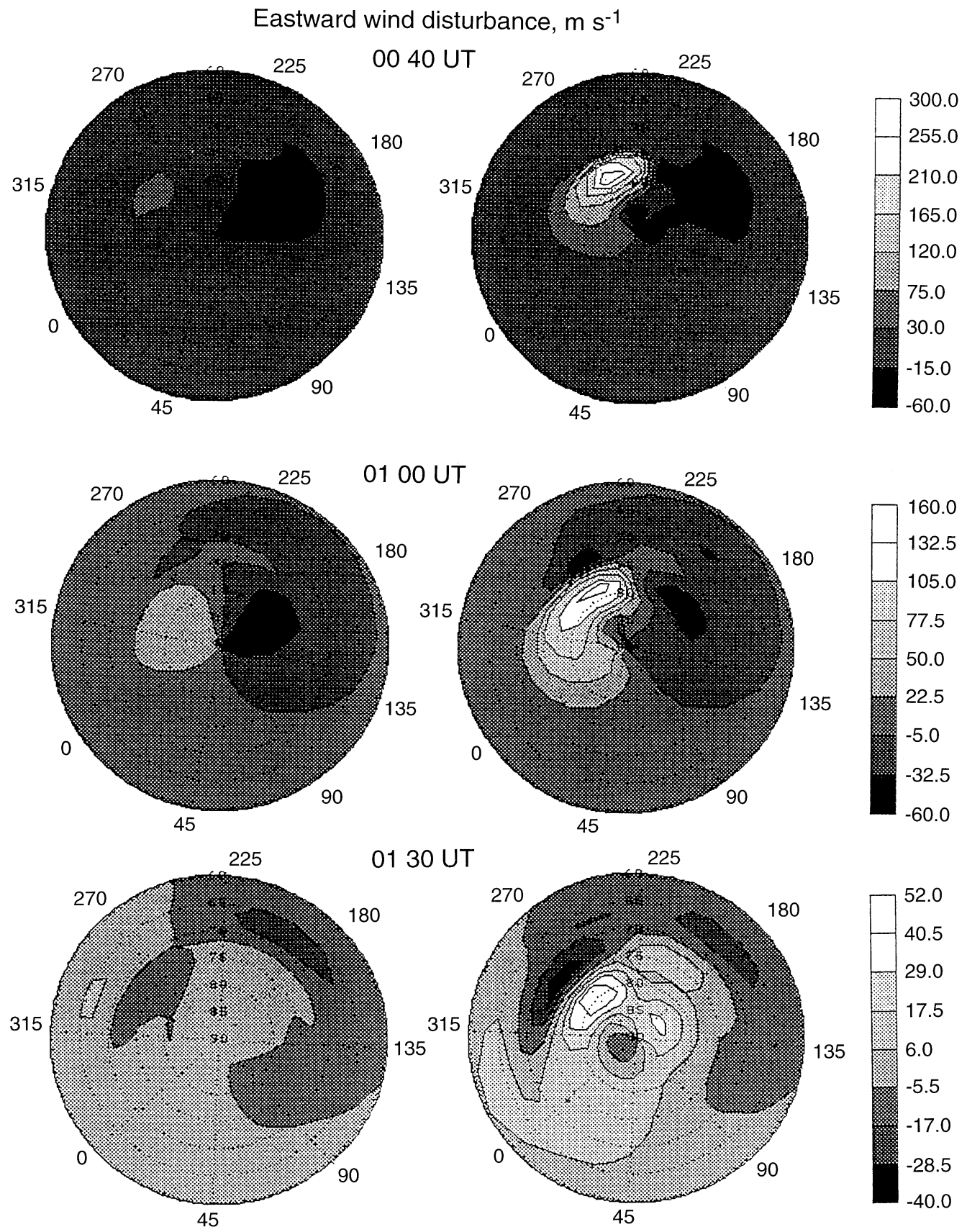

Fig. 10. The same as in Fig. 8 but for the zonal (positive eastward) thermospheric-windvelocity disturbance at $-40.0 h=300 \mathrm{~km}$ 
to empirical models (for example that by Heppner and Maynard, 1987). The disturbed potential pattern (bottom panel) obtained when the additional field-aligned currents are included, consists of three convection cells: two with positive potential values in the midday-morning sector and one with negative potential in the evening sector. Such a convection pattern corresponds to the type $\mathrm{G}$ discussed by Reiff and Burch (1985). The maximum electricfield intensities are of about $30 \mathrm{mV} \mathrm{m}^{-1}$.

Figures 8-10 show the geomagnetic polar plots $\left(60^{\circ}-90^{\circ}\right)$ of the calculated thermospheric disturbances, i.e. the differences between disturbed and undisturbed values of the calculated neutral temperature, meridional (positive northward) and zonal (positive eastward) wind velocity at $300-\mathrm{km}$ altitude. A comparison of the results shown in the left- and right-hand columns in these figures, as well as of the results presented by solid curves with and without the black circles in Figs. 5-7, demonstrates the differences between the effects caused by the joint action of the precipitation and field-aligned-current variations, and those caused by the precipitation only. It can be seen from these figures that the main differences are in the thermospheric-wind and ion-temperature disturbances in the cusp region. The latter are much more intensive (up to about $600 \mathrm{~K}$ ) at the geomagnetic latitudes $75^{\circ}-80^{\circ}$ in the case of joint precipitation and field-aligned-current action due to Joule heating of the ion gas in the cusp region, whereas the neutral-temperature increases are not so great (Figs. 6 and 8).

The most significant changes are in the variations in zonal thermospheric wind due to the ion drag. Eastward wind disturbances of about $140-200 \mathrm{~m} \mathrm{~s}^{-1}$ appear at geomagnetic latitudes $75^{\circ}-80^{\circ}$ in the midday sector (Fig. 7) and of about $200-300 \mathrm{~m} \mathrm{~s}^{-1}$ in the afternoon sector (Fig. 10). The meridional wind disturbances are about $90 \mathrm{~m} \mathrm{~s}^{-1}$ at the geomagnetic latitudes $80^{\circ}-85^{\circ}$ in the midday sector (Fig. 7) and of about $180 \mathrm{~m} \mathrm{~s}^{-1}$ in the afternoon sector (Fig. 9). They are also caused by the ion drag which acts in the opposite direction, in comparison with the pressure gradient forcing in the midday sector.

The response of electron density to the field-alignedcurrent disturbances (Fig. 5) is very localized near the $80^{\circ}$ geomagnetic latitude, being negative because of an increase in ion temperature due to Joule heating of the ion gas. The electron-temperature change is insignificant. The differences between the results of the calculations in variants 3 and 4 are seen in Figs. 6 and 7 to be largely in the ion-temperature and the zonal- and meridional-thermospheric-wind variations at the geomagnetic latitudes $75^{\circ}-85^{\circ}$

\section{Summary and conclusions}

The thermospheric and ionospheric effects of the precipitating electron flux and field-aligned-current variations in the cusp have been modelled by the use of a global numerical model of the Earth's upper atmosphere. This three-dimensional, time-dependent model describes the ionosphere, thermosphere and protonosphere of the Earth as a single system and includes the calculations of the electric fields, both of magnetospheric and thermospheric (dynamo) origin. A new version of this model, developed for studies of polar phenomena, employs variable latitudinal steps in the numerical integration scheme of the coupled equations, allowing us to enhance the latitudinal resolution of the model at those latitudes where this is necessary.

The responses of the electron concentration, ion, electron and neutral temperature, wind velocity and electricfield potential to the variations of a precipitating $0.23-\mathrm{keV}$ electron flux intensity with and without variations in the field-aligned current density in the cusp have been calculated by solving the corresponding continuity, momentum and heat-balance equations.

Four variants of the calculations have been performed: (1) the cusp position is fixed and only the sudden precipitation of $0.23-\mathrm{keV}$ electrons takes place over $30 \mathrm{~min}$; (2) the cusp is moving from $78^{\circ}$ to $73^{\circ}$ and back and the precipitation flux is linearly increased and then decreased over $1 \mathrm{~h}$; (3) the same as in variant 2 but additional field-aligned currents corresponding to IMF $B_{y}<0$ are included, being linearly increased and then decreased over $1 \mathrm{~h}$; (4) the same as in variant 3 but the additional fieldaligned currents maintain their maximum values after 0030 UT.

The main prominent feature of the results of our calculations is that the thermospheric disturbances outside the cusp are generated mainly by the thermospheric heating due to the soft electron precipitation. They reveal appreciable magnitudes at significant distances from the cusp region being noticeably larger in case of the moving region of the precipitation. For example, the meridional-windvelocity disturbance at $65^{\circ}$ geomagnetic latitude is of the same order as the background wind due to solar heating, but is oppositely directed. We can conclude from these calculations that the most distinguishable disturbances outside the cusp are those of the thermospheric wind. It means that Fabri-Perot interferometer observations outside the cusp could be used as a means of remote investigation of the cusp dynamics.

The thermospheric disturbances propagate from the cusp to lower latitudes as large-scale atmospheric gravity waves with the mean horizontal velocity of about $690 \mathrm{~m} \mathrm{~s}^{-1}$. This speed is comparable with values of about $400-718 \mathrm{~m} \mathrm{~s}^{-1}$, estimated from the observations of AGW (with periods of about $60 \mathrm{~min}$ ) during the October 1985 WAGS campaign (Rice et al., 1988; Williams et al., 1988). It is worth nothing that at the geomagnetic latitudes equatorwards from $70^{\circ}$, all disturbances have a similar form of time variation, almost independent of the time variation of the cusp disturbance. This arises because of the attenuation of the higher-frequency harmonics.

The ionospheric disturbances have appreciable magnitudes at the geomagnetic latitudes $70^{\circ}-85^{\circ}$. The electronconcentration and -temperature disturbances are caused mainly by the ionization and heating processes due to precipitation. On the other hand, the ion-temperature disturbances are influenced strongly by Joule heating of the ion gas due to the field-aligned currents and associated electric-field disturbances in the cusp. The latter strongly influence the meridional and, in particular, the zonal-wind 
disturbances via ion drag, so these disturbances can reach values of about $200-300 \mathrm{~m} \mathrm{~s}^{-1}$ in the afternoon sector at $75^{\circ}-85^{\circ}$ geomagnetic latitude.

Acknowledgements. This work is supported by Grants RLX300 from the International Science Foundations and Russian Government and 95-05-14505 from the Russian Foundation of Fundamental Investigations, and by the Grant from the SCOSTEP Bureau (1995). The authors would like to thank O. V. Martynenko for his assistance in performing the calculations. We are grateful to the referee \# 1 for very useful remarks and comments.

Topical Editor D. Alcaydé thanks M. Lockwood and A. G. Burns for their help in evaluating this paper.

\section{References}

Burns, A. G., T. L. Killeen, and R. G. Roble, A theoretical study of thermospheric composition perturbations during an impulsive geomagnetic storm, J. Geophys. Res., 96, 14153, 1991.

Cowley, S. W. H., and M. Lockwood, Excitation and decay of solar wind driven flows in the magnetosphere-ionosphere system, Ann. Geophysicae, 10, 103, 1992.

Dickinson, R. E., E. C. Ridley, and R. G. Roble, A three-dimensional general circulation model of the thermosphere, J. Geophys. Res., 86, 1499, 1981.

Dickinson, R. E., E. C. Ridley, and R. G. Roble, Thermospheric general circulation with coupled dynamics and compositions, $J$. Atmos. Sci., 41, 205, 1984.

Fuller-Rowell, T. J., A two-dimensional, high-resolution, nested-grid model of the thermosphere 1. Neutral response to an electric field "spike", J. Geophys. Res., 89, 2971, 1984.

Fuller-Rowell, T. J., and D. Rees, A three-dimensional, time-dependent global model of the thermosphere, J. Atmos. Sci., 37, 2545, 1980.

Fuller-Rowell, T. J., and D. Rees, A three-dimensional, time-dependent simulation of the global dynamical response of the thermosphere to a geomagnetic substrom, J. Atmos. Terr. Phys., 43, 701, 1981.

Fuller-Rowell, T. J., and D. Rees, Derivation of a conservation equation for mean molecular weight for a two-component gas within a three-dimensional, time-dependent model of the thermosphere, Planet. Space Sci., 31, 1209, 1983.

Fuller-Rowell, T. J., and D. Rees, Interpretation of anticipated longlived vortex in the lower thermosphere following simulation of an isolated substorm, Planet. Space Sci., 32, 69, 1984.

Fuller-Rowell, T. J., D. Rees, S. Quegan, G. J. Bailey, and R. J. Moffett, The effect of realistic conductivities on the high-latitude neutral thermospheric circulation, Planet. Space Sci., 32, 469, 1984.

Fuller-Rowell, T. J., D. Rees, S. Quegan, G. J. Bailey, and R. J. Moffett, Interactions between neutral thermospheric composition and the polar ionosphere using a coupled ionosphere-thermosphere model, J. Geophys. Res., 92, 7744, 1987.

Fuller-Rowell, T. J., D. Rees, S. Quegan, R. J. Moffett, and G. J. Bailey, Simulations of the seasonal and universal time variations of the high-latitude thermosphere and ionosphere using a coupled, three-dimensional model, Pure Appl. Geophys., 127, 189, 1988.

Fuller-Rowell, T. J., D. Rees, H. Rishbeth, A. G. Burns, T. L. Killeen, and R. G. Roble, Modelling of composition changes during F-region storms: a reassessment. J. Atmos. Terr. Phys., 53, 541, 1991.

Hardy, D. A., M. S. Gussenhoven, and E. Holeman, A statistical model of auroral electron precipitation, J. Geophys. Res., 90, 4229, 1985.

Heppner, J. P., and N. C. Maynard, Empirical high-latitude electric field models, J. Geophys. Res., 92, 4467, 1987.

Iijima, T., and T. A. Potemra, The amplitude distribution of fieldaligned currents at northern high latitudes observed by Triad. J. Geophys. Res., 81, 2165, 1976.
Ivanov-Kholodny, G. S., and A. A. Nusinov, Korotkovolnovoe izluchenie Solntza i ego vozdeistvie na verchnyuu atmospheru i ionospheru, Issled. cosmicheskogo prostransiva (Invest. Outer Space), VINITI Press, Moscow, 26, 80, 1987.

Maeda, S., T. J. Fuller-Rowell, and D. S. Evans, Zonally averaged dynamical and compositional response of the thermosphere to auroral activity during September 18-24, 1984, J. Geophys. Res., 94, 16869, 1989.

Millward, G. H., S. Quegan, R. J. Moffett, T. J. Fuller-Rowell, and D. Rees, A modelling study of the coupled ionospheric and thermospheric response to an enhanced high-latitude electric field events, Planet. Space Sci., 41, 45, 1993.

Namgaladze, A. A., Yu. N. Korenkov, V. V. Klimenko, I. V. Karpov, F. S. Bessarab, V. A. Surotkin, T. A. Glushchenko, and N. M. Naumova, Global model of the thermosphere-ionosphere-protonosphere system, Pure Appl. Geophys. A. A., 127, $219,1988$.

Namgaladze, A. A., Yu. N. Korenkov, V. V. Klimenko, I. V. Karpov, F. S. Bessarab, V. A. Surotkin, T. A. Glushchenko, and N. M. Naumova, Global numerical model of the thermosphere, ionosphere, and protonosphere of the Earth, Geomagn. Aeron., 30, $612,1990$.

Namgaladze, A. A., Yu. N. Korenkov, V. V. Klimenko, I. V. Karpov, V. A. Surotkin, and N. M. Naumova, Numerical modelling of the thermosphere-ionosphere-protonosphere system, J. Atmos. Terr. Phys., 53, 1113, 1991.

Namgaladze, A. A., Yu. N. Korenkov, V. V. Klimenko, I. V. Karpov, V. A. Surotkin, F. S. Bessarab, and V. M. Smertin, Numerical modelling of the global coupling processes in the near-earth space environment, COSPAR Coll. Ser., 5, 807, 1994.

Namgaladze, A. A., O. V. Martynenko, and A. N. Namgaladze, Global model of the upper atmosphere with variable latitudinal steps of numerical integration, IUGG XXI General Assembly, Boulder, 1995, Abstracts, GAB41F-6, B150, 1995 (and in Russian Geomagn. Aeron., 36, 89, 1996a).

Namgaladze, A. A., O. V. Martynenko, A. N. Namgaladze, M. A. Volkov, Yu. N. Korenkov, V. V. Klimenko, I. V. Karpov, and F. S. Bessarab, Numerical simulation of an ionospheric disturbance over EISCAT using a global ionospheric model, J. Atmos. Terr. Phys., 58, 297, 1996b.

Ohtani, S., T. A. Potemra, P. T. Newell, L. J. Zanetti, T. Iijima, M. Watanabe, L. G. Blomberg, R. D. Elphinstone, J. S. Murphree, M. Yamauchi, and J. G. Woch, Four large-scale field-aligned current systems in the dayside high-latitude region, J. Geophys. Res., 100, 137, 1995.

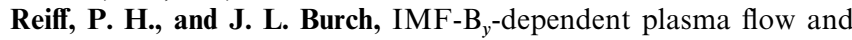
Birkeland currents in the dayside magnetosphere. 2. A global model for northward and southward IMF, J. Geophys. Res., 90, 1595, 1985.

Rice, D. D., R. D. Hunsucker, L. J. Lanzerotti, G. Growley, P. J. S. Williams, J. D. Graven, and L. Frank, An observation of atmospheric gravity wave cause and effect during the October 1985 WAGS campaign, Radio Sci., 23, 919, 1988.

Richmond, A. D., and S. Matsushita, Thermospheric response to a magnetic substorm, J. Geophys. Res., 80, 2839, 1975.

Richmond, A. D., E. C. Ridley, and R. G. Roble, A thermosphereionosphere general circulation model with coupled electrodynamics, Geophys. Res. Lett., 19, 601, 1992.

Roble, R. G., M. H. Rees, Time-dependent studies of the aurora: effects of particle precipitation on the dynamic morphology of ionospheric and atmospheric properties, Planet. Space Sci., 25, 991, 1977.

Roble, R. G., and E. C. Ridley, A thermosphere-ionosphere-mesosphere-electrodynamics general circulation model (TIMEGCM): equinox solar cycle minimum conditions $(30-500 \mathrm{~km})$, Geophys. Res. Lett., 21, 417, 1994.

Roble, R. G., J. M. Forbes, and F. A. Marcos, Thermospheric dynamics during the March 22, 1979, magnetic storm., 1. Model simulations. J. Geophys. Res., 92, 6045, 1987.

Roble, R. G., E. C. Ridley, A. D. Richmond, and R. E. Dickinson, A coupled thermosphere/ionosphere general circulation model, Geophys. Res. Lett., 15, 1325, 1988. 
Sandholt, P. E., C. J. Farrugia, L. F. Burlaga, J. A. Holtét, J. Moen, B. Lybekk, B. Jacobsen, D. Opsvik, A. Egeland, R. Lepping, A. J. Lazarus, T. Hansen, A. Brekke, and E. Friis-Christensen, Cusp/cleft auroral activity in relation to solar wind dynamic pressure, interplanetary magnetic field $B_{z}$ and $B_{y}, J$. Geophys. Res., 99, 17323, 1994.

Schunk, R. W., A mathematical model of the middle and highlatitude ionosphere, Pure Appl. Geophys., 127, 255, 1988.

Shepherd, G. S., Dayside cleft aurora and its ionospheric effects, Rev. Geophys. Space Phys., 17, 2017, 1979.

Sojka, J. J., Global-scale physical models of the F-region ionosphere, Rev. Geophys., 27, 371, 1989.

Sojka, J. J., and R. W. Schunk, A model study of how electric field structures affect the polar cap F-region, J. Geophys. Res., 93, 884, 1988.

Sojka, J. J., and R. W. Schunk, Theoretical study of the seasonal behavior of the global ionosphere at solar maximum, J. Geophys. Res., 94, 6739, 1989.
Taguchi, S., M. Sugiura, J. D. Winningham, and J. A. Slavin, Characterization of the IMF- $B_{y}$-dependent field-aligned currents in the cleft region based on DE 2 observations, J. Geophys. Res., 98, 1393, 1993

Williams, P. J. S., G. Growley, K. Schlegel, T. S. Virdi, I. McCrea, G. Watkins, N. Wade, J. K. Hargreaves, T. Lachlan-Cope, H. Muller, J. E. Baldwin, P. Warner, A. P. van Eyken, M. A. Hapgood, and A. S. Rodger, The generation and propagation of atmospheric gravity waves observed during the Worldwide Atmospheric Gravity-wave study (WAGS), J. Atmos. Terr. Phys., 50, 323, 1988

Yamauchi, M., R. Lundin, and J. Woch, The interplanetary magnetic field $B_{y}$ effects on large-scale field-aligned currents near local noon: contributions from cusp part and non-cusp part, J. Geophys. Res., 98, 5761, 1993. 